\title{
MENINGKATKAN PEMAHAMAN SISWA DALAM PEMBELAJARAN \\ PENDIDIKAN AGAMA ISLAM PADA MATERI SHALAT JENAZAH DENGAN MENGGUNAKAN METODE DRIIL DI KELAS XI IPA 2 SMA NEGERI 1 RANDANGAN
}

(Improve students understanding in islamic religious education learning in general prayer materials using driil methods in class XI IPA 2 high school of 1 Randangan)

\section{Sulastri Ali}

Sekolah Menengah Atas Negeri 1 Randangan

Jl. Trans Sulawesi, Desa Motolohu, Kecamatan Randanngan

Kabupaten Pohuwato, Provinsi Gorontalo, Kode Pos 96268

Email: alisulastri79@gmail.com

\begin{abstract}
ABSTRAK
Penelitian ini bertujuan untuk meningkatkan aktivitas belajar siswa melalui pembelajaran metode Drill dan meningkatkan kemampuan siswa dalam kooperatif antara satu dengan yang lainnya dalam membahas sebuah materi di dalam kelas. Subjek penelitian ini adalah siswa kelas XI IPA 2 SMA Negeri 1 Randangan sebanyak 28 siswa. Penelitian ini dilaksanakan dengan 2 siklus, teknik pengumpulan data dengan observasi dan tes tertulis. Pada awal kegiatan belajar mengajar pada siklus I pertemuan pertama dalam aspek pengamatan kegiatan guru pada kategori Sangat Baik 25\%; Baik 37,5\% dimana belum mencapai ketuntasan, sedangkan pada pengamatan hasil belajar siswa pada kegiatan/proses belajar kategori penilaian A(90 - 100) hanya 17,9\%; B (80 -89) 32,1\%; C (70 -79) 39,9\%; D ( <70 )10,7\% sehingga dapat dilihat belum mencapai nilai standar ketuntasan. Pada siklus I pertemuan kedua yang terlihat secara klasikal siswa telah memahami/menganalisis pada proses belajar mengajar sehingga hasilnya dapat dilihat dalam aspek pengamatan kegiatan guru pada kategori Sangat Baik 41,67\%; Baik 50\%; Cukup Baik 8,3\%; Kurang Baik 0\%, dimana sudah mencapai ketuntasan. Pada hasil pengamatan proses belajar siswa pada kategori penilaian A (90 - 100) 45,46\%; B (80 - 89 ) 54,54\%; C (70 -79) 0\%; D (<70) 0\%. Dengan demikian dapat dilihat pada siklus ini telah mencapai nilai ketuntasan.
\end{abstract}

Kata Kunci : Pemahaman siswa; metode drill; sholat jenazah; randangan

\section{ABSTRACT}

This study aimed to improve student learning activities by learning the Drill method and improving students' ability to cooperate to discuss the material in the classroom. The subjects of this study were 28 students of class XI IPA 2 of SMA Negeri 1 Randangan. This research was conducted in 2 cycles. The data collection techniques were observation and written test. At the beginning of teaching and learning activities, in the first cycle of the first meeting in the aspect of observing teacher activities in the Very Good 25\% category; Good 37.5\% where it has not reached completeness, while the observation of student learning outcomes in the activity/learning process category A (90-100) only 17.9\%; B (80-89) 32.1\%; C (70 -79) $39.9 \%$; D $(<70) 10.7 \%$ so it can be seen that it has not reached the standard value of completeness. In the first cycle of the second meeting, which was seen classically, the students had understood/analyzed the teaching and learni ng process so that the results could be seen in the aspect of observing teacher activities in the Very Good category $41.67 \%$; Good 50\%; Good Enough 8.3\%; Not good 0\%, where it has reached completeness. On the results of observations of the student learning process in the assessment category A (90-100) 45.46\%; B (80 - 89) 54.54\%; C (70-79) $0 \%$; D $(<70) 0 \%$. Thus it can be seen that this cycle has reached the completeness value.

Keywords: Students understanding; drill method; funeral prayers; randangan 


\section{PENDAHULUAN}

Salah satu program dan kegiatan pembangunan bidang pendidikan diarahkan untuk pengembangan profesionalisme guru. Dilihat dari posisinya, guru merupakan unsur penentu utama bagi keberhasilan pendidikan. Untuk itu guru dituntut untuk kreatif dan banyak ide dalam menentukan strategi, metode, maupun media yang akan digunakan pada saat proses belajar mengajar agar menciptakan suasana belajar yang menyenangkan bagi siswa dan tidak membosankan (Ariani, 2011).

Salah satu faktor penting dalam pendidikan adalah proses belajar mengajar, dimana kualitas proses belajar sangat mempengaruhi mutu pendidikan itu sendiri. Kendala yang sering dihadapi adalah sebagian guru belum mengembangkan metode pembelajaran secara maksimal (Darsono. 2000). Dalam proses belajar mengajar ada kecenderungan guru sangat dominan peranannya, sehingga guru berfungsi sebagai sumber belajar dan pemegang otoritas tertinggi dalam proses belajar mengajar ketika berada di depan kelas. Guru sebagai pengajar diharapkan

tidak mendominasi kegiatan pembelajaran, tetapi membantu menciptakan situasi yang kondusif serta memberikan motivasi dan bimbingan agar siswa dapat mengembangkan potensi dan kreativitas melalui kegiatan belajar. Menentukan metode atau kegiatan belajar merupakan salah satu langkah penting yang dapat menunjang keberhasilan pencapaian tujuan pembelajaran. Maka dari itu dalam pembelajaran hendaknya guru menerapkan variasi metode pembelajaran dan guru menekankan agar peserta didik aktif dalam kegiatan belajar, sehingga guru berperan sebagai fasilitator dan motivator. Termasuk guru pendidikan agama islam ditutut agar lebih kreatif dalam menciptakan suasana mengajar yang menyenagkan bagi siswa (Etin. 2012).

Dalam pembelajaran Pendidikan Agama Islam (PAI) di Kelas KELAS XI IPA 2 SMA Negeri 1 Randangan yang materinya mengupas tentang shalat yakni praktek shalat jenazah masih mengalami kendala dalam penyampaian pembelajaran maupun dalam penerimaan siswa tentang pembelajaran shalat tersebut. Selama ini perhatian dan penerimaan pembelajaran ini masih kurang jadi butuh adanya model pembelajaran yang sesuai (Hamalik. 2007). Untuk mengupayakan minat siswa tehadap bahan ajar, dibutuhkan yang namanya pembelajaran yang menarik minat siswa untuk belajar, 
menyenangkan dan menggiring mereka kearah tujuan pembelajaran yang hendak dicapai. Proses perubahan sistem pembelajaran kearah yang hendak dicapai haruslah diikuti dengan menerapkan suatu model pembelajaran. Melihat karakteristik materi yang ada dalam panduan Standar Kompetensi (SK) dan Kompetensi Dasar $(\mathrm{KD})$, materi ini menurut hemat penulis cocok sekali dengan metode Drill. Di SMA Neg. 1 Randangan yang penulis teliti banyak disaksikan siswa belum mengetahui langkah-langkah shalat sunat, termasuk juga shalat jenazah. Penulispun mencoba mengkritisi teknik pembelajaran pendidikan AgamaIslam khususnya dalam soal praktek shalat. Metode mengajarkan pendidikan Agama Islam khususnya dalam tatcara shalat, selama ini ternyata hanya menggunakan metode ceramah dan anjuran karena hal tersebut dianggap merupakan hal yang biasa. Sepengetahuan penulis penelitian tentang hal tersebut belum ditemui. Dari kenyataan tersebut penulis ingin menerapkan satu metode mengajar "drill" untuk meningkatkan penguasaan pemahaman siswa terhadap materi "Praktek Shalat Jenazah".

Sebuah perkara yang dianggap baru bila hanya dikomunikasikan secara verbal saja tentu akan mendapatkan hasil yang kurang memuaskan baik bagi sipenerima maupun dalam penerapannya. That practice make perfect (Gunawan
Hupoyo; 1991) pribahasa ini menjadi panduan untuk diterapkannya metode drill. Berdasarkan latar belakang tersebut diatas maka penulis ingin mengadakan penelitian tindakan kelas dngan judul "Meningkatkan pemahaman siswa dalam pembelajaran Pendidikan Agama Islam pada materi shalat jenazah dengan menggunakan metode Driil di kelas XI IPA 2 SMA Negeri 1 Randangan."

\section{Rumusan Masalah}

Rumusan masalah penelitian ini di susun dalam kalimat pertanyaan sebagai berikut :

1. Adakah peningkatan perhatian siswa Kelas XI IPA 2 SMA Negeri 1 Randangan pada pelajaran Pendidikan Agama Islam?

2. Apakah Siswamampu untuk tampil mempraktekkan shlat jenazah di hadapan guru dan siswa?

3. Apakah dengan menggunakan metode drill dapat meningkatkan hasil belar siswa?

\section{Tujuan Penelitian}

Penelitian ini bertujuan untuk memperoleh gambaran lengkap tentang hal-hal di bawah ini :

1. Mampu memperagakan tata cara menshalatkan jenazah

2. Mampu untuk tampil mempraktekkan shalat mempraktekkan di hadapan guru dan siswa 
3. Meningkatkan hasil belar siswa

\section{METODE PENELITIAN}

Metode Drill tepat digunakan apabila pelajaran dimaksudkan untuk melatih ulang pelajaran yang sudah diberikan dan atau sedang berlangsung. Selain itu pelajaranpun bertujuan melatih keterampilan anak dalam mengerjakan sesuatu. Metode ini dipergunakan untuk memperkuat daya tanggapan anak terhadap pelajaran. Untuk mengurangi sisi negatifnya tersebut, maka penulis menyusun langkah-langkah sebagai berikut :

1. Guru menyampaikan kompetensi yang akandicapai

2. Guru memberikan materi tentang Shalat Jenazah atau jenazah

3. Siswa mempersiapkan perlengkapan yang akan digunakan pada saat proses pembelajaran dalam hal ini praktek shalat

4. Membagi siswa kedalam beberapa kelompok.

5. Masing masing kelompok membahas bersama tentang tata cara shalat jenaza.

6. Guru mempersilahkan masing-masing kelompok untuk mempraktekkan tata cara shalat jenazah yang sudah dibahas bersama kelompok masing-masing.

\section{Pelaksanaan Penelitian}

Penelitian Tindakan Kelas (PTK) ini dilaksanakan di SMA Negeri 1
Randangan. Subyek penelitian adalah siswa kelas XI IPA 2 yang berjumlah 23 orang siswa terdiri dari 12 orang laki-laki dan 11 orang perempuan.

\section{Prosedur Penelitian}

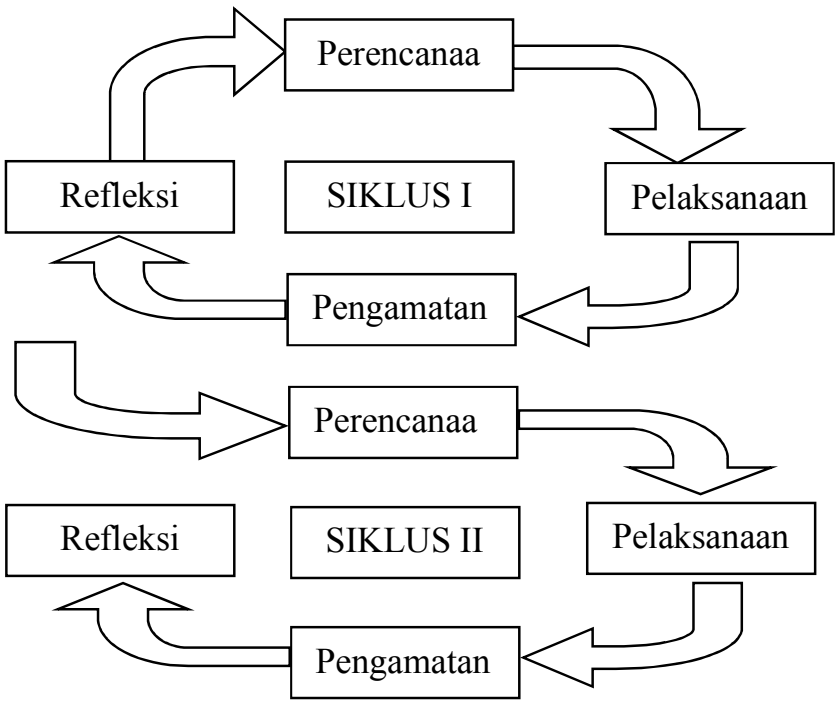

Gambar 1. Spiral penelitian tindakan kelas (Arikunto, 2009)

\section{HASIL DAN PEMBAHASAN}

Tabel 1. Hasil belajar pada observasi awal

\begin{tabular}{lccc}
\hline No & $\begin{array}{c}\text { Kategori } \\
\text { Penilaian }\end{array}$ & Frekuensi & Presentase \\
\hline 1. & $\mathrm{~A}$ & 6 & $27,27 \%$ \\
2. & $\mathrm{~B}$ & 5 & $22,73 \%$ \\
3. & $\mathrm{C}$ & 9 & $40,90 \%$ \\
4. & $\mathrm{D}$ & 2 & $9,10 \%$ \\
\hline & Jumlah & 22 & $100 \%$ \\
\hline
\end{tabular}




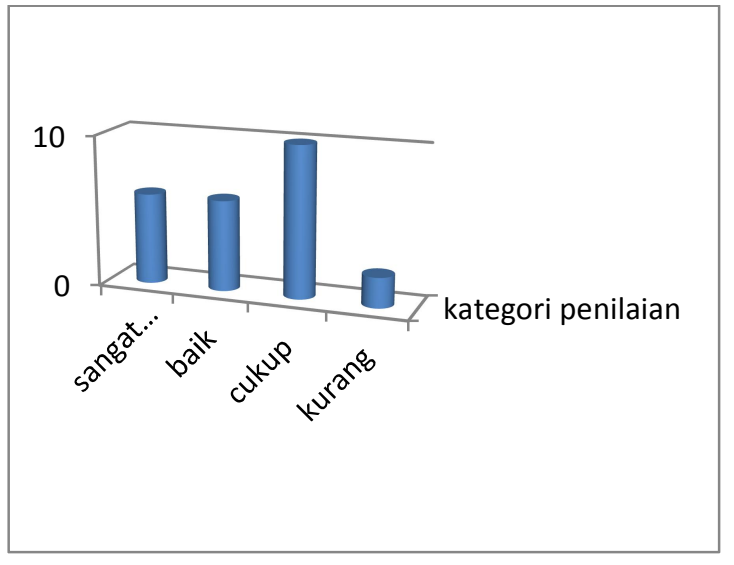

Gambar 2. Hasil belajar pada observasi awal

\section{Analisis Hasil Pengamatan Kegiatan}

Belajar Mengajar (KBM) Siklus 1 sebagai berikut :

Tabel 2. Persentase hasil proses belajar Siswa Siklus 1 pertemuan pertama

\begin{tabular}{|c|c|c|c|}
\hline No & $\begin{array}{l}\text { Kriteria } \\
\text { Penilaian }\end{array}$ & Frekuensi & $\begin{array}{c}\text { Presentase } \\
(\%)\end{array}$ \\
\hline 1 & A & 1 & $16,67 \%$ \\
\hline 2 & B & 7 & $29,16 \%$ \\
\hline 3 & $\mathrm{C}$ & 9 & $41,67 \%$ \\
\hline 4 & D & 5 & $12,5 \%$ \\
\hline & Jumlah & 22 & $100 \%$ \\
\hline
\end{tabular}

Tabel 3. Persentase hasil tes untuk menghitung ketuntasan belajar siswa siklus 1 pertemuan I

\begin{tabular}{ccc}
\multicolumn{3}{c}{ siklus 1 pertemuan I } \\
\hline $\begin{array}{c}\text { Hasil Tes siklus 1 } \\
\text { Pertemuan 1 }\end{array}$ & $\begin{array}{c}\text { siswa } \\
(22)\end{array}$ & $\begin{array}{c}\text { Ketercapai } \\
\text { an (\%) }\end{array}$ \\
\hline $\begin{array}{c}\text { Siswa yang tuntas } \\
\text { Siswa yang tidak } \\
\text { tuntas }\end{array}$ & 17 & $77,27 \%$ \\
\hline Jumlah & 5 & $13,63 \%$ \\
\hline
\end{tabular}

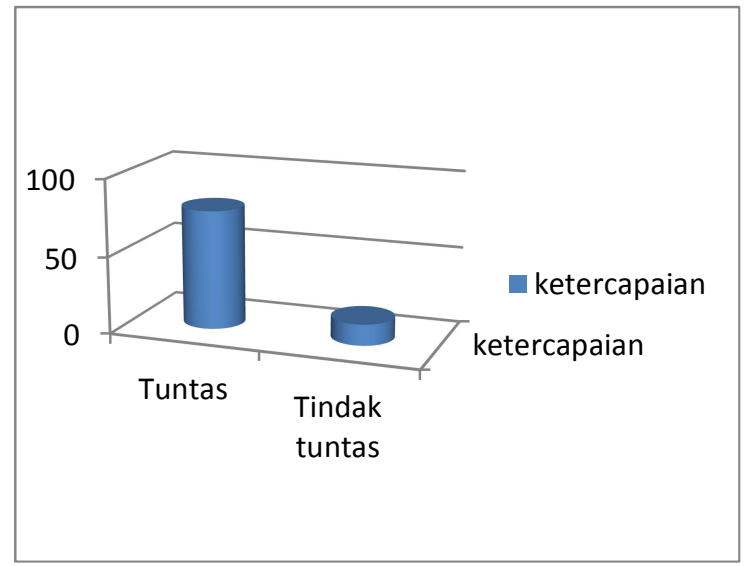

Gambar 3. Hasil tes untuk menghitung ketuntasan belajar siswa siklus 1 pertemuan I

Tabel 4. Presentase penilaian proses siklus 1 pertemuan kedua

\begin{tabular}{cccc}
\multicolumn{4}{c}{ 1 pertemuan kedua } \\
\hline No & $\begin{array}{c}\text { Kriteria } \\
\text { Penilaian }\end{array}$ & Frekuensi & $\begin{array}{c}\text { Presentase } \\
(\%)\end{array}$ \\
\hline 1 & $\mathrm{~A}$ & 10 & $45,46 \%$ \\
2 & $\mathrm{~B}$ & 12 & $54,54 \%$ \\
3 & $\mathrm{C}$ & 0 & $0 \%$ \\
4 & $\mathrm{D}$ & 0 & $0 \%$ \\
\hline & Jumlah & 22 & $100 \%$ \\
\hline
\end{tabular}

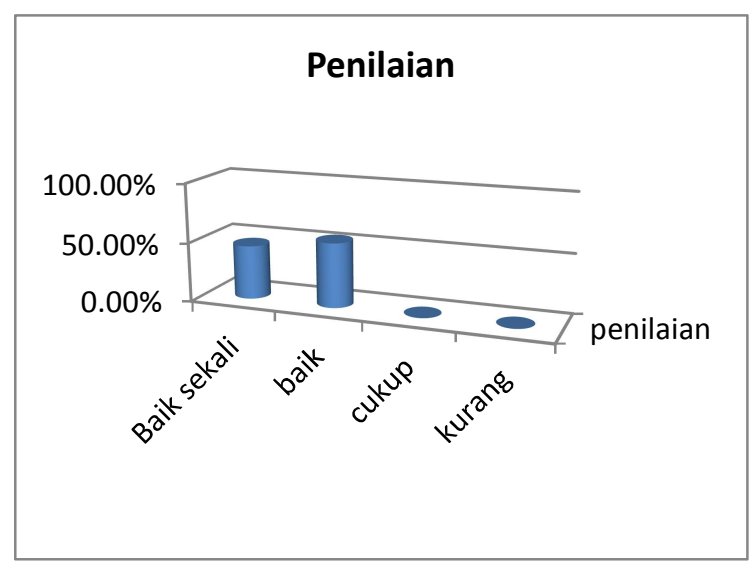

Gambar 4. Presentase ketercapaian hasil tes siklus 1 pertemuan kedua 
Tabel 5. Persentase hasil tes untuk menghitung ketuntasan belajar siswa siklus 1 pertemuan II

\begin{tabular}{ccc}
\hline $\begin{array}{c}\text { Hasil Tes siklus 1 } \\
\text { Pertemuan 2 }\end{array}$ & $\begin{array}{c}\text { Jumlah } \\
\text { siswa (24) }\end{array}$ & $\begin{array}{c}\text { Ketercapai } \\
\text { an (\%) }\end{array}$ \\
\hline $\begin{array}{c}\text { Siswa yang tuntas } \\
\text { Siswa yang tidak } \\
\text { tuntas }\end{array}$ & 22 & $100 \%$ \\
\hline Jumlah & 0 & $0 \%$ \\
\hline
\end{tabular}

Tabel 6. Persentase hasil proses belajar Siswa Siklus 1 pertemuan pertama

\begin{tabular}{cccccc}
\hline \multirow{2}{*}{ No } & Kriteria & \multicolumn{2}{c}{ Siklus 1 Pertemuan 1 } & \multicolumn{2}{c}{ Siklus 1 Pertemuan 2 } \\
\cline { 3 - 6 } & Penilaian & Frekuensi & Presentase (\%) & Frekuensi & Presentase (\%) \\
\hline 1 & $\mathrm{~A}$ & 1 & $16,67 \%$ & 10 & $45,46 \%$ \\
\cline { 3 - 6 } 2 & $\mathrm{~B}$ & 7 & $29,16 \%$ & 12 & $54,54 \%$ \\
3 & $\mathrm{C}$ & 9 & $41,67 \%$ & 0 & $0 \%$ \\
\cline { 5 - 6 } & $\mathrm{D}$ & 5 & $12,5 \%$ & 0 & $0 \%$ \\
\hline & Jumlah & 22 & $100 \%$ & 22 & $100 \%$ \\
\hline
\end{tabular}

Hasil pengamatan mengenai pelaksanaan pembelajaran yang menggunakan model pembelajaan Drill pada mata pelajaran Pendidikan Agama Islam melalui penilaian evaluasi, dimana menjadikan hasil belajar siswa dan daya serap siswa dapat terlihat jelas, yakni :

a. Pada awal kegiatan belajar mengajar peneliti menggunakan model pembelajaran Drill tersebut pada siklus I pertemuan pertama dalam aspek pengamatan kegiatan guru pada kategori Sangat Baik 25\%; Baik $37,5 \%$ dimana belum mencapai ketuntasan, sedangkan pada pengamatan hasil belajar siswa pada kegiatan/proses belajar kategori penilaian $\mathrm{A}(90$ - 100) hanya $17,9 \%$; $\mathrm{B}(80-89) \quad 32,1 \%$; $\mathrm{C}(70-79) \quad 39,9 \%$; $\mathrm{D}(<70) \quad 10,7 \%$ sehingga dapat dilihat belum mencapai nilai standar ketuntasan. Begitu pula dilihat dari hasil belajar siswa melalui evaluasi yang diadakan diakhir proses belajar, siswa yang tuntas hanya sekitar $64,2 \%$ sehingga dapat dilihat belum mencapai nilai standar ketuntasan.

b. Pada awal kegiatan belajar mengajar yakni menggunakan model pembelajaran Drill tersebut pada siklus I pertemuan ke dua yang terlihat secara klasikal siswa telah memahami/menganalisis pada proses belajar mengajar sehingga hasilnya dapat dilihat dalam aspek pengamatan kegiatan guru pada kategori Sangat Baik 41,67\%, Baik 50\%, Cukup Baik 8,3\%, Kurang Baik 0\%, dimana sudah mencapai ketuntasan, pada hasil pengamatan proses belajar siswa pada 
kategori penilaian A $(90-100)$ $45,46 \%$; B (80 - 89) 54,54\%; C (70 79) $0 \%$; D $\quad(<70) \quad 0 \%$. Dengan demikian dapat dilihat pada siklus ini telah mencapai nilai ketuntasan.

\section{KESIMPULAN}

Berdasarkan uraian yang terdapat pada deskripsi hasil penelitian dan pembahasannya pada bab sebelumnya, maka dapat diambil kesimpulan sebagai berikut :

1. Penelitian tindakan kelas yang dilaksanakan selama satu siklus 2 pertemuan dengan menggunakan model pembelajaran Drill telah dapat menunjukan adanya aktivitas yang mencapai peningkatan hasil belajar siswa.

2. Penelitian tindakan kelas yang telah dilaksanakan selama satu siklus 2 pertemuan didasarkan pada kelemahan yang terjadi pada siklus satu pertemuan pertama yakni hasil belajar dan proses pembelajaran yang belum optimal, kelemahan yang terjadi pada proses pembelajaran telah dilaksanakan perbaikan pada siklus 1 pertemuan ke 2 sebagai tindak lanjut, sehinnga pembelajaran meningkat berdasarkan tahapan penelitian.

3. Terlihat jelas adanya peningkatan aktivitas belajar siswa dalam proses pembelajaran Jika guru menggunakan model pembelajaran Drill pada mata pelajaran Pendidikan Agama Islamdi kelas XI IPA 2 SMA Negeri 1 Randangan.

\section{DAFTAR PUSTAKA}

Ariani, I. 2011. Pendekatan, Strategi Metode Pembelajaran. Malang. PPPPTK Pendidikan Agama Islam dan IPS.

Arikunto, S. 2009. Penelitian Tindakan Kelas. Jakarta. Bumi Aksara.

Darsono. 2000. Belajar Dan Pembelajaran. Semarang: CV IKIP Semarang PRESS.

Etin S. 2012. Strategi Pembelajaran. Jakarta. Bumi Aksara.

Gunawan H, 1991. The Boyhood of Ronggowarsito. Jakarta : PT. Gramedia Pustaka Utama.

Hamalik O. 2007. Metode Belajar \& Kesulitan-Kesulitan Belajar. Bandung. Tarsito. 